\title{
Presurgical cleft lip and palate orthopedics: an overview
}

This article was published in the following Dove Press journal:

Clinical, Cosmetic and Investigational Dentistry

31 May 2017

Number of times this article has been viewed

\section{Ibtesam Alzain' \\ Waeil Batwa ${ }^{2}$ \\ Alex Cash ${ }^{3}$ \\ Zuhair A Murshid ${ }^{2}$}

'Pediatric Dentistry, ${ }^{2}$ Orthodontic Department, Faculty of Dentistry, King Abdulaziz University, Jeddah, Saudi Arabia; ${ }^{3} \mathrm{Cleft}$ Lip and Palate Orthodontics, Queen Victoria NHS Foundation Trust, South Thames Cleft Service, London, UK

Correspondence: Waeil Batwa Orthodontic Department, Faculty of Dentistry, PO Box 80209, Jeddah, Saudi Arabia

Tel +966565I20520

Email wbatwa@gmail.com
Abstract: Patients with cleft lip and/or palate go through a lifelong journey of multidisciplinary care, starting from before birth and extending until adulthood. Presurgical orthopedic (PSO) treatment is one of the earliest stages of this care plan. In this paper we provide a review of the PSO treatment. This review should help general and specialist dentists to better understand the cleft patient care path and to be able to answer patient queries more efficiently. The objectives of this paper were to review the basic principles of PSO treatment, the various types of techniques used in this therapy, and the protocol followed, and to critically evaluate the advantages and disadvantages of some of these techniques. In conclusion, we believe that PSO treatment, specifically nasoalveolar molding, does help to approximate the segments of the cleft maxilla and does reduce the intersegment space in readiness for the surgical closure of cleft sites. However, what we remain unable to prove equivocally at this point is whether the reduction in the dimensions of the cleft presurgically and the manipulation of the nasal complex benefit our patients in the long term.

Keywords: presurgical orthopedic, nasoalveolar molding, cleft lip and palate

\section{Introduction}

Providing a high-quality care to cleft patients can be as challenging as the myriad of clinical presentations of orofacial clefting that occur. The child born with an orofacial cleft will usually require multidisciplinary, advanced and lifelong treatments. This complex clinical care challenges those who provide that care, and even pioneering countries such as the UK are faced with such challenges. Nearly 15 years ago, the investigation by the Clinical Standard Advisory Group (CSAG) ${ }^{1}$ highlighted the paucity of clinical excellence in Britain and recommended a more centralized service with better training facilities for specialists in order to improve clinical outcomes for patients. The importance of understanding the cleft lip and/or palate (CLP) patient care pathway is of paramount importance in order to be able to support the patients throughout their treatment.

Infant patients who present with a complete bony cleft (Figure 1) may benefit from treatment in advance of the primary surgical repair of their lip and palate. Teams may offer initial treatment of their cleft to try to reduce the dimensions of the cleft with a process of treatments known as presurgical orthopedics (PSOs). CLP PSO treatment is usually provided by a cleft team clinician, commonly the orthodontist. Table 1 shows the different team members. 


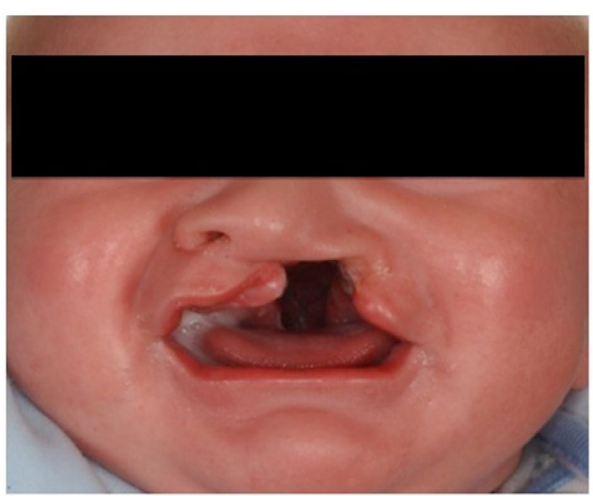

Figure I Complete unilateral cleft lip and palate patient.

Table I Different members of cleft team with suggested age of involvement

Team members involved in cleft patient Age of involvement treatments

\begin{tabular}{ll}
\hline $\begin{array}{l}\text { Geneticist } \\
\text { Psychologist and social worker }\end{array}$ & $\begin{array}{l}\text { Prenatal } \\
\text { Specialist nurse }\end{array}$ \\
$\begin{array}{l}\text { Cleft surgeon } \\
\text { Dentist, pediatric dentist, orthodontist, and } \\
\text { restorative dentist }\end{array}$ & $\begin{array}{l}\text { Immediately after birth } \\
\text { After birth }\end{array}$ \\
$\begin{array}{l}\text { Ear, nose, and throat surgeons } \\
\text { Pediatrician }\end{array}$ & After birth \\
Nutritionist & After birth \\
Audiologist & After birth \\
Speech-language therapist pathologist & After birth \\
\hline & 18 months to adulthood \\
\hline
\end{tabular}

The goals of repair of CLP are: ${ }^{2}$

- help patients to develop normal speech;

- restore dentition and oral functions;

- improve hearing;

- minimize facial difference;

- attain social acceptability of cleft individuals; and

- increase assimilation into society (psychological support)

- restore/reconstruct facial and oral anatomy.

In this review, we discuss the indications for PSOs and explore the literature and protocols that exist in this early infant treatment.

\section{What are PSO treatments?}

Molding the perioral structures of the infant with a CLP has been a clinical technique in use since before the 1950s. Attempts are made to reposition the nasolabial and maxillary segments closer to each other. It has been mainly used in the first few weeks after birth and in the months prior to palate repair. PSO treatment involves primarily the active movement of the maxillary fragments with passive or active alveolar plates prior to the surgical repair; this is often referred to as alveolar molding. Whenever a nasal stent is added to the alveolar plate, it is considered as nasoalveolar molding (NAM). Approximately half of surveyed centers in Europe used PSO techniques with mostly passive plates, whereas some teams also used a plate to assist with feeding (Figure 2). ${ }^{3}$

\section{Objectives of PSOs}

The main objectives of this presurgical step of treatment have been cited as:

- facilitating intra-oral feeding;

- improving maxillary growth;

- improving the projection of the nasal tip;

- reducing nasal deformity;

- facilitating primary lip, nasal, and alveolar surgeries; and

- retracting and repositioning the premaxilla more posteriorly in patients with bilateral cleft.

\section{Controversies around PSOs}

The use of orthopedic appliances has been always controversial, and there is much debate on this topic in the literature. It has been shown that it is possible to manipulate the infant's oronasal complex, to narrow cleft width, to correct the anatomical position of the maxillary segment, and to improve the angulation of the palatal shelves to more horizontal position (Table 2). ${ }^{4}$ Some researchers question whether these shortterm outcomes will have any beneficial long-term effects on the overall treatment outcome (Table 3).

\section{Techniques of PSOs}

Different approaches or techniques are suggested to achieve an orthopedic effect; they include alveolar molding, lip strap, NAM, and lip adhesion. The approach selection is usually determined by the operator preference and the type of cleft to be treated (Table 4).

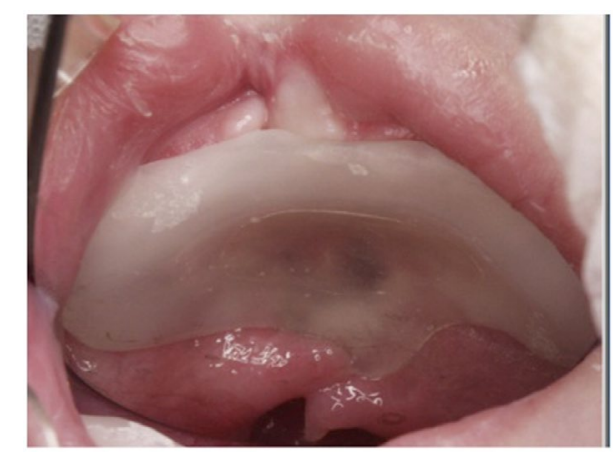

Figure 2 Passive plate acts as a feeding plate. 
Table 2 Suggested advantages of presurgical orthopedic treatment

\begin{tabular}{ll}
\hline Surgery & Aids in the surgical repair of the lip and palate by reducing defect width of the palatal and alveolar ridge, which in turn will reduce \\
lip tension and benefits wound healing postoperatively \\
Prevents initial collapse after surgery and crossbites \\
Achieves symmetrical arch form \\
Improves position of alar base \\
Less extensive orthodontic treatment at later ages \\
Improved growth of the maxilla as repositioning of the bony segments will help in future growth and development \\
Reduced tongue interference with the palatal shelves may encourage the normal growth of the palatal shelves, thus allowing \\
Spontaneous reduction in the width of the cleft \\
Improved speech development due to improved physiological tongue function and position (prevents twisting and dorsal position \\
of the tongue in the cleft). ${ }^{4}$ The improvement was significant in children aged I-3 years; ${ }^{13}$ this was seen as the ability of the child to \\
Function \\
produce longer sentences. However, this improvement diminished in children aged 6 years ${ }^{13}$ \\
Improved feeding (less danger of aspiration); however, there is no evidence to support this \\
Better nose breathing and decreased nasal regurgitation \\
A positive psychological effect on the parents
\end{tabular}

Table 3 Views of the opponent to presurgical orthopedic treatment

\begin{tabular}{ll}
\hline Cost-effectiveness & Neonatal maxillary orthopedics is a complex and expensive therapy that is ineffective and unnecessary because \\
parents are obliged to travel frequently to the treatment center and endure an increased burden of care \\
There is no significant improvement in parents' satisfaction \\
The overall cost of treatment is significantly high ${ }^{4}$ \\
Neonatal maxillary orthopedics restricts maxillary development as a result of the molding process \\
There are no apparent long-term effects on facial growth in either vertical or anteroposterior dimensions. However, \\
there is some evidence emerging that those patients who have had NAM do have improved nasal anatomy. ${ }^{14-16}$ \\
Although some feel that infants who have PSOs treatment look much better than those who do not have, with each \\
passing year, it becomes more difficult to tell which patients had the segments repositioned and which patients did \\
not ${ }^{17}$ \\
Influences speech negatively due to delayed surgery of the hard palate \\
It is not necessary for feeding or orthodontic reasons, ${ }^{4}$ did not improve feeding efficiency or general body growth, ${ }^{18}$ \\
and did not improve deviated swallowing characteristics ${ }^{19}$
\end{tabular}

Abbreviations: PSOs, presurgical orthopedics; NAM, nasoalveolar molding.

Table 4 Presurgical orthopedic technique

\begin{tabular}{|c|c|c|}
\hline Cleft type & Technique & Rational \\
\hline Cleft of lip and alveolus & Lip strapping & $\begin{array}{l}\text { Little facial and alveolar distortion that can be corrected with lip strapping } \\
\text { alone }\end{array}$ \\
\hline Unilateral cleft lip/palate & $\begin{array}{l}\text { Passive appliance } \\
\text { Active appliance and lip strapping }\end{array}$ & $\begin{array}{l}\text { Can help to keep tongue away and facilitate lateral palatal shelf growth } \\
\text { when there is only little distortion } \\
\text { When there is significant distortion on the cleft area }\end{array}$ \\
\hline Bilateral cleft lip/palate & $\begin{array}{l}\text { Lip strapping and active/passive appliance or } \\
\text { nasoalveolar molding }\end{array}$ & $\begin{array}{l}\text { The premaxilla is usually prominent and everted and needs to be placed } \\
\text { back, in addition to the distorted alveolar processes. }\end{array}$ \\
\hline Cleft of hard/soft palate & Passive appliances & Helps to keep tongue away and facilitates lateral palatal shelf growth \\
\hline
\end{tabular}

\section{Alveolar molding}

The maxillary segments of the child with a bony cleft are amenable to a degree of molding and repositioning if suitable appliances are used in the neonatal period. The ultimate goal is to attain an end-to-end position of the alveolar processes before lip operation. Appliances used to attain these positions of the alveolar processes are described as active (Figure 3) or passive appliances (Figure 4).
Active appliances mold the separate alveolar processes into position by applying active forces on them or, in other words, by directing them to grow or to be moved into a preplanned position. The construction of these appliances starts by creating an intraoral impression of the cleft infant and then pouring this impression into the plaster. Either the model is then sectioned and the acrylic mouth plate made on the adjusted plaster cast or a spring may be added to the 

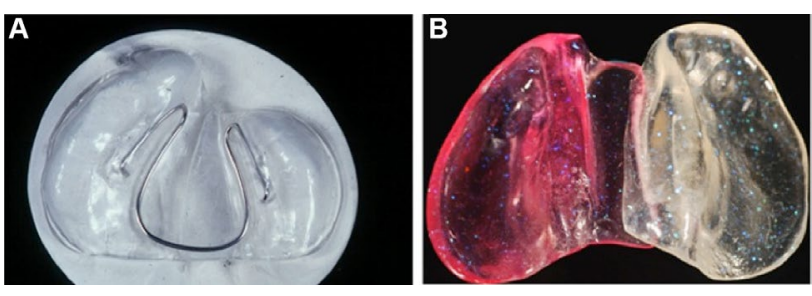

Figure 3 (A and B) Different shapes and designs for active appliances.

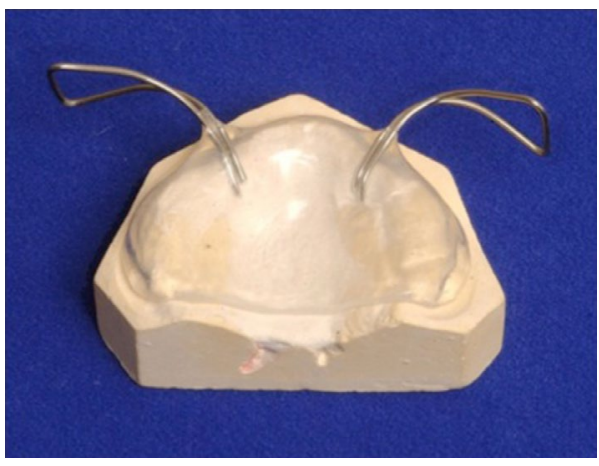

Figure 4 Passive appliance.

plate to direct the alveolar processes to adapt a position where more normal maxillary arch form would be achieved (Figure 5).

Passive appliances are slightly different from active appliances. They are constructed on the poured study model and fit directly onto the alveolar processes. The clinician at the chairside may add flowable acrylic or remove acrylic in a process called negative sculpting. This alteration in the shape of the fit surface of the appliance will allow the alveolar processes to grow passively as planned by the clinician (Figure 6).

\section{Lip strap/lip taping}

A combination of intra-oral appliances and/or extra-oral orthopedic strapping (Figure 7) can be used in preparation for primary lip and plate surgery. In combination with the intraoral mouth plates, external tapes and elastics may be strapped to the cheeks to provide some external forces in the alveolar molding process. Elastic forces will exert a retracting, backward pressure against the protruding premaxilla, and careful use of forces on the cleft segments will improve their positions and allow definitive lip skin and muscle repair. In asymmetric cases, a lip bumper or pillow can be added to the tape to help to steer the segments to the desired position.

If PSO correction is not able to be definitively completed, then the improved relations of the cleft segments may facilitate a temporary skin repair of the lip in a surgical operation known as a lip adhesion.
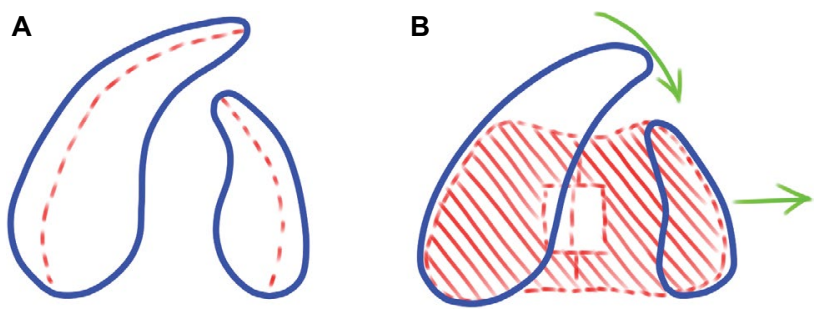

Figure 5 Active appliance, designed to expand and to move the lesser alveolar segment laterally.

Notes: (A) The two alveolar segments are not aligned as shown by the red doted lines. (B) An acrylic appliance was placed (red shaded area) and as a result of molding the greater alveolar segment was moved towards the lesser one while the lesser segment was moved laterally by expansion to allow this. The green arrows show the direction of movement of both segments. The greater segment may then be retracted and molded into a more natural position.
A
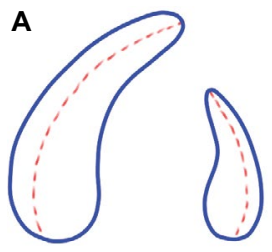

B

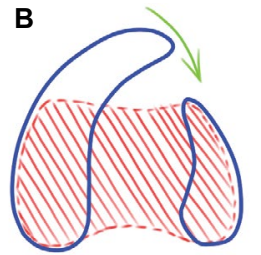

C

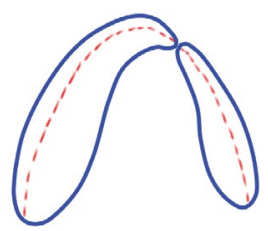

Figure 6 Passive appliance.

Notes: No need to move the smaller alveolar segment laterally; there is enough space for larger segment to mold. (A) The two alveolar segments are not aligned as shown by the red doted lines. (B) An acrylic appliance was placed (shaded area) and as a result of molding the greater alveolar segment was moved towards the lesser one. The green arrow shows the direction of movement of the segments. Note that the lesser segment did not move. (C) The two segments after alignment.

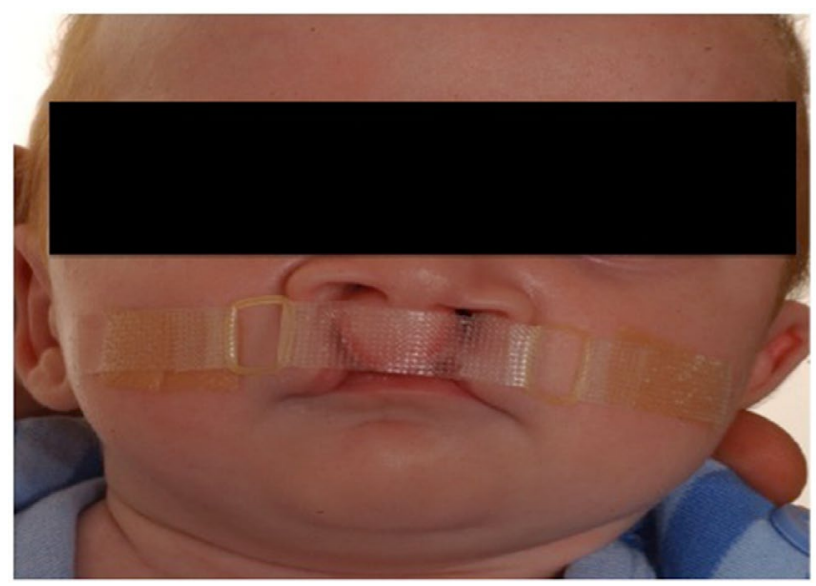

Figure 7 Lip strapping of the infant upper lip.

\section{NAM}

PSO has evolved, and NAM is a technique that has been adopted by several teams across the world. In this approach, a nasal stent is attached to the intra-oral mouth plate and is designed to improve nasolabial anatomy. It is reported that columella lengthening, reduction in alar asymmetry, and recovery of nasal tip projection can be achieved (Figure 8). The use of nasal stents in bilateral CLP in combination with lip tapes and elastics can lengthen the deficient columella. ${ }^{5}$ It has been proven that NAM improved surgical outcome for cleft patient, as it is effective in reducing hard and soft tissue deformity. ${ }^{6}$ Table 5 summarizes some of the findings of recent comparative studies. 


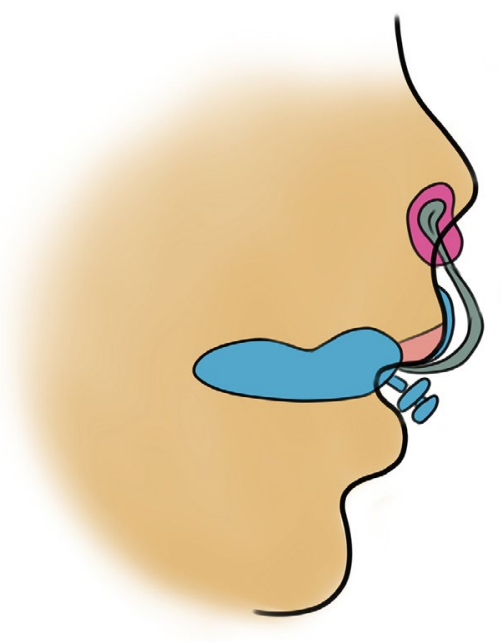

Figure 8 Naso alveolar molding appliance.

\section{PSOs between orthodontics and pediatric dentistry}

In the literature, the role of the pediatric dentists and orthodontists may vary within different multidisciplinary teams, where the pediatric dentists' role is mainly focused on oral anticipatory guidance to pregnant mothers and giving preventive advice and care as soon as the first primary tooth erupt in the CLP patient as well as restorative care as needed. ${ }^{7}$ However, it is not uncommon in some care centers to find that the role of the pediatric dentists starts much earlier than that, within the first few days after birth in constructing the PSO appliance. ${ }^{89}$ More commonly, the orthodontist is the responsible specialist who is involved in the construction of the PSO device. ${ }^{7}$ Nonetheless, who carries out the early treatment of CLP patients mainly depends on the setting of the multidisciplinary team within a specific hospital. It is therefore more important that the specialist has training in handling and managing young infants and that the procedure of taking an impression takes place in a hospital where the emergency team is ready to intervene if necessary.

\section{Lip adhesion surgery}

Many teams adopt a presurgical protocol to dovetail with their surgical protocols. Where PSO is not used, the use of previously discussed lip adhesion technique may be offered as the first stage of a two-stage repair of the lip. For the more displaced clefts, often bilateral cases, an initial bilateral lip adhesion is used where repair of the muscles is usually completed at a second surgical stage, perhaps 6 months later.

Bilateral lip adhesion acts like PSOs and helps to control the protrusive premaxilla and may enable a later definitive repair. Although there is no evidence that it would improve the outcome, it is often technically very difficult to close wide clefts with one surgical procedure. In addition, the repair of unilateral cleft can be difficult if the premaxilla has rotated to the repaired side. The use of lip adhesion within the first 3 months followed by a definitive lip revision usually permits the surgeon to perform surgery in stages as the face changes. However, definitive lip surgery can be performed at an earlier age ( 3 months) if the lip is to be repaired using one-stage technique (Table 6).

Surgical timing varies significantly from team to team and country to country, where some lip repairs are completed neonatally, perhaps as early as 3 weeks in some centers; in others, it may be completed at $\geq 3-6$ months. However, it is quite reasonable to wait until the patient can undergo general anesthetic safely (the rule of "over ten" is usually followed [10 weeks of age, 10 pounds, and $10 \mathrm{~g} / \mathrm{dL}$ of hemoglobin]).

The main goals of cleft lip surgery treatment are to 1) restore lip and nasal form; 2) reconstruct oral competence and orofacial muscle dynamicity; 3 ) improve cosmetic appearance; and 4) minimize maxillary growth disturbance (American Society of Maxillofacial Surgeons, 1994). ${ }^{10}$ Many techniques are discussed in the literature.

Table 5 Summary of findings from recent nasoalveolar molding studies

\begin{tabular}{|c|c|c|}
\hline Author & Objective & Findings \\
\hline Chang et $\mathrm{al}^{20}$ & $\begin{array}{l}\text { Comparison of two nasoalveolar moldingtechniques in unilateral } \\
\text { complete cleft lip patients (modified Figueroa and the modified } \\
\text { Grayson) }\end{array}$ & $\begin{array}{l}\text { The two nasoalveolar moldingtechniques produced similar } \\
\text { nasal outcomes }\end{array}$ \\
\hline Liao et $\mathrm{al}^{21}$ & $\begin{array}{l}\text { Compare outcomes of two nasoalveolar moldingtechniques } \\
\text { for bilateral cleft nose deformity (modified Figueroa and the } \\
\text { modified Grayson) }\end{array}$ & $\begin{array}{l}\text { Figueroa technique is associated with fewer oral mucosal } \\
\text { complications and more efficiency }\end{array}$ \\
\hline Clark et $\mathrm{al}^{22}$ & $\begin{array}{l}\text { Evaluate the long-term effectiveness of presurgical nasoalveolar } \\
\text { molding }\end{array}$ & $\begin{array}{l}\text { A long-term clinical improvement in nasal and lip anatomy of } \\
\text { unilateral complete cleft lip patients }\end{array}$ \\
\hline Shetty et $\mathrm{al}^{23}$ & $\begin{array}{l}\text { Evaluate the effects of nasoalveolar molding in complete } \\
\text { unilateral cleft lip and palate infants presenting for treatment at } \\
\text { different ages }\end{array}$ & $\begin{array}{l}\text { Younger infants at the age of } \mathrm{I} \text { month benefited better than } \\
\text { infants presented for treatment at the age of } \mathrm{I}-5 \text { months }\end{array}$ \\
\hline
\end{tabular}


Table 6 Timing of lip surgery

\begin{tabular}{lll}
\hline Age & Orthodontics & Surgery \\
\hline $3-4$ weeks & Pre surgical orthopedics & Lip adhesion (or wait until 3 months) \\
3 months & Repair of the cleft lip, nose, and anterior palate \\
6 months & Definite lip surgery (if lip adhesion was done at 4 weeks) or repair of the cleft palate, following the \\
& repair of the cleft lip, nose, and anterior palate at 3 months \\
\hline
\end{tabular}

Every surgeon also can incorporate some modifications and variations depending on the case. However, the best therapeutic techniques in CLP surgery are those that have minimal negative effects on maxillofacial growth, and so ultimately as few and as conservative surgical episodes as possible are best when a patient has further natural growth to come.

Negative effects on growth may not become evident until after the pubertal growth spurt; however, whenever they do occur, it is usually associated with maxillofacial problems in all three planes of space and these may be reflected in the dental occlusion with incisor and buccal segment cross bites and/or cleft-centered open bite. These problems may add to the complexity of the later treatments and increase the need for orthognathic surgery. Interestingly, when investigators looked at unrepaired clefts of the palate, they found no interference with facial growth. ${ }^{11,12}$

\section{Conclusion}

Despite the fact that PSO treatments were popularized $>60$ years ago, the evidence related to this topic is still weak and inconclusive, mainly due to difficulty of study design and data collection. In addition, each procedure a patient undergoes muddies the waters and reduces our ability to tease out the effects of an individual treatment. All of this happens in a growing patient over a 20 -year period.

As a result, different treatment protocols for different cleft subtypes were developed, according to Mossey et $\mathrm{al}^{3}$ - "The absence of a sound evidence base for selection of treatment protocols was shown by a striking diversity of practices across Europe for surgical care of just one cleft subtype - unilateral complete cleft of lip, alveolus, and palate". Surprisingly, of 201 teams doing primary surgical repair for this cleft type, 194 different protocols were being practiced.

We know that PSO and NAM do help to approximate the segments of the cleft maxilla and do reduce the intersegment space in readiness for the surgical closure of cleft sites. However, what we remain unable to prove equivocally at this point is whether the reduction in the dimensions of the cleft presurgically and the manipulation of the nasal complex benefit our patients in the long term.
Our surgical colleagues anecdotally reported that they found smaller cleft gaps more straightforward to close than larger ones, but, as yet, the evidence does not support that the repair of a smaller cleft gap will lead to a better outcome.

The parents of the children in the images have provided written informed consent for the images to be published in this review.

\section{Disclosure}

The authors report no conflicts of interest in this work.

\section{References}

1. Sandy J, Williams A, Mildinhall S, et al. The Clinical Standards Advisory Group (CSAG) Cleft Lip and Palate Study. Br J Orthod. 1998; 25(1):21-30.

2. Mosahebi A, Kangesu L. Cleft lip and palate. Surgery (Oxford). 2006; 24(1):33-37.

3. Mossey PA, Little J, Munger RG, Dixon MJ, Shaw WC. Cleft lip and palate. Lancet. 2009;374(9703):1773-1785.

4. Prahl C, Kuijpers-Jagtman AM, van't Hof MA, Prahl-Andersen B. A randomised prospective clinical trial into the effect of infant orthopaedics on maxillary arch dimensions in unilateral cleft lip and palate (Dutchcleft). Eur J Oral Sci. 2001;109(5):297-305.

5. Penfold C, Dominguez-Gonzalez S. Bilateral cleft lip and nose repair. Br J Oral Maxillofac Surg. 2011;49(3):165-171.

6. Retnakumari N, Ajith P, Divya S, Meenakumari S. Nasoalveolar molding treatment in presurgical infant orthopedics in cleft lip and cleft palate patients. Arch Med Health Sci. 2014;2(1):36-47.

7. Ahmed MM, Brecht LE, Cutting CB, Grayson BH. 2012 American Board of Pediatric Dentistry College of Diplomates annual meeting: the role of pediatric dentists in the presurgical treatment of infants with cleft lip/cleft palate utilizing nasoalveolar molding. Pediatr Dent. 2012;34(7):e209-e214.

8. Rivkin CJ, Keith O, Crawford PJ, Hathorn IS. Dental care for the patient with a cleft lip and palate. Part 1: from birth to the mixed dentition stage. Br Dent J. 2000;188(2):78-83.

9. Rivkin CJ, Keith O, Crawford PJ, Hathorn IS. Dental care for the patient with a cleft lip and palate. Part 2: the mixed dentition stage through to adolescence and young adulthood. Br Dent J. 2000;188(3):131-134.

10. Mitchell JC, Wood RJ. Management of cleft lip and palate in primary care. J Pediatr Health Care. 2000;14(1):13-19.

11. Mars M, Houston WJ. A preliminary study of facial growth and morphology in unoperated male unilateral cleft lip and palate subjects over 13 years of age. Cleft Palate J. 1990;27(1):7-10.

12. Mars M, James DR, Lamabadusuriya SP. The Sri Lankan Cleft Lip and Palate Project: the unoperated cleft lip and palate. Cleft Palate J. 1990; 27(1):3-6.

13. Konst EM, Rietveld T, Peters HF, Kuijpers-Jagtman AM. Language skills of young children with unilateral cleft lip and palate following infant orthopedics: a randomized clinical trial. Cleft Palate Craniofac J. 2003;40(4):356-362. 
14. Abbott MM, Meara JG. Nasoalveolar molding in cleft care: is it efficacious? Plast Reconstr Surg. 2012;130(3):659-666.

15. Garfinkle JS, King TW, Grayson BH, Brecht LE, Cutting CB. A 12-year anthropometric evaluation of the nose in bilateral cleft lip-cleft palate patients following nasoalveolar molding and cutting bilateral cleft lip and nose reconstruction. Plast Reconstr Surg. 2011;127(4): 1659-1667.

16. Spengler AL, Chavarria C, Teichgraeber JF, Gateno J, Xia JJ. Presurgical nasoalveolar molding therapy for the treatment of bilateral cleft lip and palate: a preliminary study. Cleft Palate Craniofac J. 2006;43(3): 321-328.

17. Ross RB. Treatment variables affecting facial growth in complete unilateral cleft lip and palate. Cleft Palate J. 1987;24(1):5-77.

18. Masarei AG, Wade A, Mars M, Sommerlad BC, Sell D. A randomized control trial investigating the effect of presurgical orthopedics on feeding in infants with cleft lip and/or palate. Cleft Palate Craniofac $J$. 2007;44(2):182-193.
19. Knosel M, Fendel C, Jung K, Sandoval P, Engelke WG. Presurgical orthopedics by drink plates does not significantly normalize deglutition in infants with cleft lip and palate. Angle Orthod. 2016;86(2):315-323.

20. Chang CS, Wallace CG, Pai BC, et al. Comparison of two nasoalveolar molding techniques in unilateral complete cleft lip patients: a randomized, prospective, single-blind trial to compare nasal outcomes. Plast Reconstr Surg. 2014;134(2):275-282.

21. Liao YF, Wang YC, Chen IJ, Pai CJ, Ko WC, Wang YC. Comparative outcomes of two nasoalveolar molding techniques for bilateral cleft nose deformity. Plast Reconstr Surg. 2014;133(1):103-110.

22. Clark SL, Teichgraeber JF, Fleshman RG, et al. Long-term treatment outcome of presurgical nasoalveolar molding in patients with unilateral cleft lip and palate. J Craniofac Surg. 2011;22(1):333-336.

23. Shetty V, Vyas HJ, Sharma SM, Sailer HF. A comparison of results using nasoalveolar moulding in cleft infants treated within 1 month of life versus those treated after this period: development of a new protocol. Int J Oral Maxillofac Surg. 2012;41(1):28-36.
Clinical, Cosmetic and Investigational Dentistry

\section{Publish your work in this journal}

Clinical, Cosmetic and Investigational Dentistry is an international, peer-reviewed, open access, online journal focusing on the latest clinical and experimental research in dentistry with specific emphasis on cosmetic interventions. Innovative developments in dental materials, techniques and devices that improve outcomes and patient satisfac-

\section{Dovepress}

tion and preference will be highlighted. The manuscript management system is completely online and includes a very quick and fair peerreview system, which is all easy to use. Visit http://www.dovepress. com/testimonials.php to read real quotes from published authors. 